\title{
Discography for disc cysts is obsolete
}

\author{
Laurens J. L. De Cocker • Lucas M. L. De Cocker • \\ Johannes van Loon $\cdot$ Philippe Demaerel
}

Received: 24 August 2009 / Accepted: 18 February 2010/Published online: 12 March 2010

(C) Springer-Verlag 2010

\section{Dear Editor,}

We recently encountered a disc cyst in a 32-year-old man with refractory low back pain and radiation into the left L5 dermatome since almost 1 year. MRI revealed a liquidcontaining cyst with extension into the left lateral recess of L5 and scalloping of the adjacent vertebral body (Fig. 1). This radiological sign is indicative of a long-standing process as it is the result of bone remodeling. The cyst caused dorsal displacement and significant compression of the thecal sac and left L5 root. The cyst was removed through a left L4 hemilaminectomy. A small annular fissure on the L4-L5 disc was noted after cyst removal, and subsequently, a discectomy was performed. After surgery, the low back pain and sciatica disappeared. Histological examination of the cyst wall exhibited chondrocytes and fibrillary stroma of disc material with areas of myxoid degeneration.

Disc cysts (also known as discal cysts) are rare cystic lesions in the ventrolateral epidural space. They are located at L4-L5 more often than at other lumbar levels, and they occur mostly in young men who present with refractory low back pain and sciatica. Disc cysts were first described one decade ago and distinguished from ganglion cysts of the posterior longitudinal ligament (PLL) by means of their cyst-disc

L. J. L. De Cocker $(\bowtie) \cdot$ P. Demaerel

Department of Radiology, University Hospitals Leuven,

Herestraat 49,

3000 Leuven, Belgium

e-mail: laurens.decocker@uz.kuleuven.ac.be

\section{M. L. De Cocker}

Department of Neurosurgery, Algemeen Ziekenhuis Turnhout, Turnhout, Belgium

J. van Loon

Department of Neurosurgery, University Hospitals Leuven, Leuven, Belgium communication at discography [4]. Ganglion cysts of the PLL [7] and disc cysts differ from juxtafacet cysts [10] by virtue of a ventral location, an intimate or pedicled attachment to the annulus fibrosus or PLL, and absent connection with a degenerative facet joint. Unlike juxtafacet cysts, disc cysts and ganglion cysts of the PLL are both walled-in by fibrous connective tissue without a synovial lining and frequently show myxoid degeneration. Chondrocytes could be demonstrated in the cyst wall of our case and in only a very few other disc cysts reported in the literature [9]. Because of the clinical, radiological, surgical, and histological similarities between disc cysts and ganglion cysts, Marshman et al. [6] suggested that their distinction on the basis of disc space communication is unnecessary. For the same reason, they also proposed to use the term "disc cyst" for both disc cysts and ganglion cysts of the PLL.

Discography is an invasive diagnostic procedure in which radiopaque contrast medium is injected into the nucleus pulposus. In disc cysts, this technique can be used to assess disc-cyst communication and to reproduce radiating pain into the affected leg [8]. As explained above, disc-cyst communication at discography was originally employed as a means to distinguish disc cysts from ganglion cysts of the PLL. Nevertheless, discography was not used in nearly all of the reported ganglion cysts of the PLL, and the same is true for some reports on disc cysts [2, $3,5]$. The reason is that patients were either treated conservatively $[2,3]$ or the disc-cyst communication was evaluated surgically [5]. This can be achieved by direct visualization of a connection between the cyst and its corresponding disc or by observation of a defect in the annulus fibrosus after cyst removal [6, 8]. The only remaining importance of disc-cyst communication lies in the fact that its presence is generally regarded as an indication for discectomy in addition to cystectomy. 


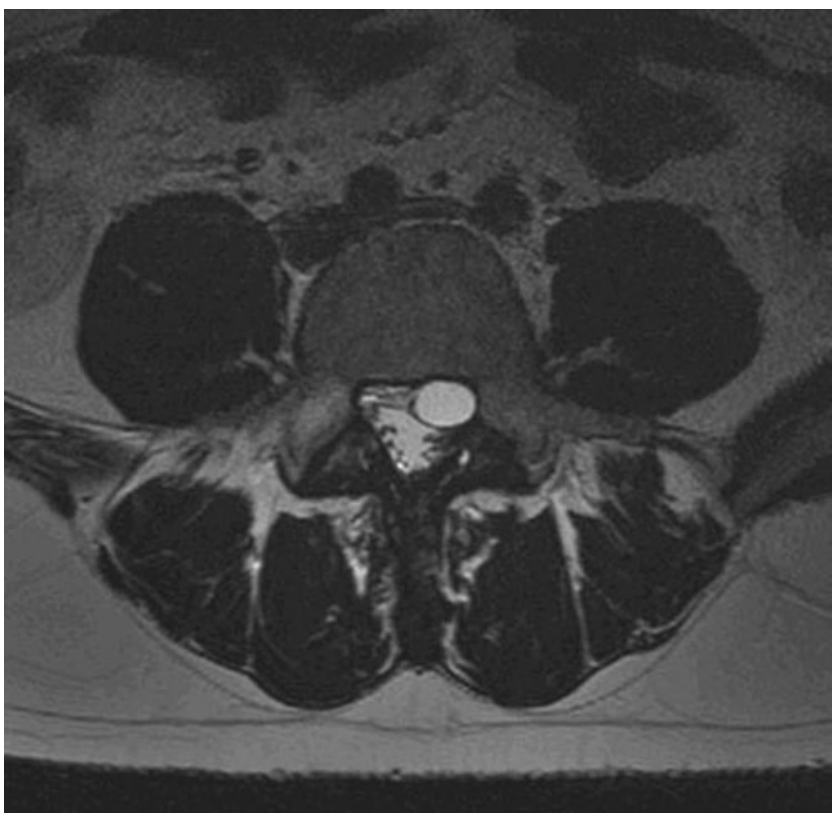

Fig. 1 Axial T2-weighted MR image shows an oval cystic lesion in the ventrolateral epidural space. The cyst extends into the left lateral recess and causes scalloping of the adjacent posterior vertebral body

Discectomy is performed in this situation in order to prevent cyst recurrence. Because of the paucity of recurrent disc cysts reported in the literature, however, the association between disc-cyst communication and disc cyst recurrence still needs to be validated. As mentioned, the reproduction of radiating pain might be a second motivation for discography. However, this indication has also been found redundant because patients usually present with sciatica that is clearly linked to nerve root compression by the disc cyst $[1,8]$. In the author's mind and experience, discography has no place in the diagnosis of entities such as the one presented.

\section{References}

1. Chiba K, Toyama Y, Matsumoto M, Maruiwa H, Watanabe M, Nishizawa $T$ (2001) Intraspinal cyst communicating with the intervertebral disc in the lumbar spine: discal cyst. Spine 26:2112-2118

2. Chou D, Smith JS, Chin CT (2007) Spontaneous regression of a discal cyst. J Neurosurg Spine 6(1):81-84

3. Demaerel P, Eerens I, Goffin J, Wilms G (2001) Spontaneous regression of an intraspinal disc cyst. Eur Radiol 11(11):2317-2318

4. Kono K, Nakamura H, Inoue Y, Okamura T, Shakudo M, Yamada R (1999) Intraspinal extradural cysts communicating with adjacent herniated disks: imaging characteristics and possible pathogenesis. AJNR Am J Neuroradiol 20:1373-1377

5. Lee HK, Lee DH, Choi CG, Kim SJ, Suh DC, Kahng SK, Roh SW, Rhim SC (2006) Discal cyst of the lumbar spine: MR imaging features. Clin Imaging 30(5):326-330

6. Marshman LA, Benjamin JC, David KM, King A, Chawda SJ (2005) "Disc cysts" and "posterior longitudinal ganglion cysts": synonymous entities? Report of three cases and literature review. Neurosurgery 57:818

7. Mizutamari M, Sei A, Fujimoto T, Taniwaki T, Mizuta H (2009) L5 radiculopathy caused by a ganglion cyst of the posterior longitudinal ligament in a teenager. Spine J 9(4):e11-e14

8. Nabeta M, Yoshimoto H, Sato S, Hyakumachi T, Yanagibashi Y, Masuda T (2007) Discal cysts of the lumbar spine: report of five cases. J Neurosurg Spine 6(1):85-89

9. Okada K, Saito H, Nishida J, Miyakoshi N, Takahashi S, Nagasawa H, Suzuki N, Chida S (2007) Discal cyst associated with myxoid change and apoptosis of herniated disc materials. Ups J Med Sci 112(1):39-47

10. Sabo RA, Tracy PT, Weinger JM (1996) A series of 60 juxtafacet cysts. Clinical presentation, the role of spinal instability, and treatment. J Neurosurg 85:560-565 